RESEARCH ARTICLE

\title{
Spatial variability assessment in Central Farm Soils of Horticultural College and Research Institute, Periyakulam, Tamil Nadu using GIS techniques
}

\author{
Sellamuthu K $\mathbf{M}^{1 *}$, Kumaraperumal $\mathbf{R}^{2}$ and Malathi $\mathbf{P}^{1}$ \\ $1 *$ Department of Natural Resource Management, Horticultural College and Research Institute, Periyakulam-625604 \\ ${ }^{2}$ Department of Remote Sensing and GIS, Tamil Nadu Agricultural University, Coimbatore-641003
}

\begin{abstract}
A total number of 201 surface soil samples were collected encompassing the fields of Central Farm of Horticultural College and Research Institute, Periyakulam, Tamil Nadu. The GPS data (Latitude ${ }^{\circ} \mathrm{N}$ and Longitude ${ }^{\circ} \mathrm{E}$ ) were recorded for each sampling site by using GPS-Garmin eTrex Vista HCX model. Field maps were collected and field number wise digitization was done. Soil samples were processed and anlaysed for soil physic-chemical and fertility parameters. Results indicated that soil samples were neutral to alkaline in reaction, non saline, and slightly calcareous to non calcareous in nature. Soil fertility groupings under percent category indicated that the soils were medium in soil organic carbon, low in available nitrogen, medium to high in available phosphorus, medium to high in available potassium, and low in available sulphur. With respect to DTPA extractable micronutrients, Fe, Zn, $\mathrm{Mn}$ and $\mathrm{Cu}$ were found to dominate by low to medium, low, high, medium to high categories, respectively. HWS-Boron was also recorded under the high category. The nutrient index values of the samples indicated a high status for organic carbon, available $\mathrm{P}$ and $\mathrm{K}$, while medium for available $\mathrm{N}$ and adequate for available sulphur. With respect to micro nutrients, nutrient index values indicated that adequate for DTPA-Zn and very high for DTPA-Fe, Mn, Cu, and HWS-B. Thematic maps generated on the individual parameters depicted the spatial variability of parameters in the Central Farm of Horticultural College and Research Institute, Periyakulam. In the identified areas of poor fertility status, nutrient deficiency has to be eliminated by the application of organic and /or inorganic sources to maintain sustainable soil fertility status. Soil test-based fertilizer recommendations and micronutrients are to be followed to mitigate nutrient deficiencies and achieve sustained crop production and soil fertility.
\end{abstract}

Key words: GIS; Nutrient status; Spatial variability; Thematic maps.

\section{INTRODUCTION}

Soil is the medium for plant growth and hence, in-depth insight on soil is a prerequisite for planning, monitoring, and developing strategies viz., optimum land, water, fertilizer use, and management aiming at high returns. The regional variation in the yield of crops is primarily due to natural factors like soil and climate. For sustained production of crops and soil health, maintenance of nutrient and moisture availability have to be maintained and managed carefully. A continuous decline in soil fertility endangers the fertility and productivity of the soil. Cropping patterns, leaching, erosion, etc., lead to the loss of fertile soil and nutrients every year. Continued cropping patterns without restoring nutrients in the soil will reduce its natural fertility and crop yields will decline. Soil testing provides the nutrient status of soils and forms the basis for the fertilizer prescription for maximizing the crop yield.

Advanced technologies like Global Positioning System (GPS) and Geographic Information System (GIS) support in collecting georeferenced soil samples and generating spatial variability maps of nutrients (Sharma, 2004). Soil fertility mapping is possible by the integration of GIS and GPS. These techniques help in taking decisions to improve agricultural approaches towards balanced nutrition. Geographic information system has emerged as a powerful tool for spatial analysis of natural resources and database management. It is an efficient and versatile tool to automate soil data transformation into soil information (Kasthuri Thilagam and Sivasamy, 2013). In the present study, an attempt has been made to evaluate the 
soil fertility status and their spatial variability in the Central farm of Horticultural College and Research Institute, Periyakulam, Tamil Nadu. An appraisal of the potentialities and constraints of the farm soils is essential in the context of improving the productivity and increasing the economic returns of the farm without deteriorating the natural resources.

\section{MATERIAL AND METHODS}

\section{Collection of soil samples}

A total of 201 surface soil samples were collected from the fields of Central Farm of Horticultural College and Research Institute, Periyakulam, Tamil Nadu. The geo-coordinates (Latitude ${ }^{\circ} \mathrm{N}$ and Longitude ${ }^{\circ} \mathrm{E}$ ) were recorded for each sampling site using GPS (Figure 1).

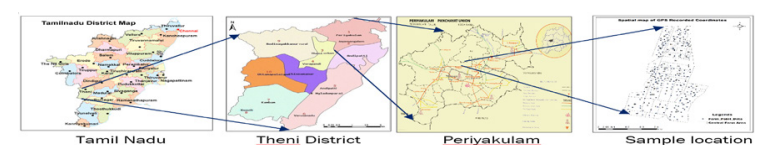

Figure 1.Geocordiantes for the locations of soil sampling

\section{Analysis of soil samples}

Soil samples were air-dried, sieved through a 2 $\mathrm{mm}$ sieve, labeled, and stored. For the estimation of organic carbon, processed soil samples were sieved with a $0.5 \mathrm{~mm}$ sieve. The soil samples were analyzed for pH and EC (Jackson, 1973), organic carbon (Walkley and Black, 1934), available nitrogen (Subbiah and Asija, 1956), available phosphorus (Olsen et al.,1954), available potassium (Stanford and English, 1949), available sulphur (Williams and Steinbergs, 1959), available $\mathrm{Zn}, \mathrm{Fe}, \mathrm{Cu}$, and $\mathrm{Mn}$ (Lindsay and Norvell, 1978) and available Boron (Berger and Truog, 1944).

The analytical results of each soil sample were categorized as low, medium, and high for organic carbon (OC) and macronutrients; as deficient, moderate, and sufficient based on the critical limits for available sulphur and micronutrients as followed in Tamil Nadu (Table 1).

Table 1. Critical levels of nutrients for low, medium, and high categories

\begin{tabular}{cccc}
\hline Nutrient & Low & Medium & High \\
\hline O.C. $\left(\mathrm{g} \mathrm{kg}^{-1}\right)$ & $<5.0$ & $5.0-7.5$ & $>7.5$ \\
$\mathrm{~N}\left(\mathrm{~kg} \mathrm{ha}^{-1}\right)$ & $<280$ & $280-450$ & $>450$ \\
$\mathrm{P}\left(\mathrm{kg} \mathrm{ha}^{-1}\right)$ & $<11$ & $11-22$ & $>22$ \\
$\mathrm{~K}\left(\mathrm{~kg} \mathrm{ha}^{-1}\right)$ & $<118$ & $118-280$ & $>280$ \\
$\mathrm{~S}\left(\mathrm{mg} \mathrm{kg}^{-1}\right)$ & $<10$ & $10-15$ & $>15$ \\
$\mathrm{Fe}\left(\mathrm{mg} \mathrm{kg}^{-1}\right)$ & $<3.7$ & $3.7-8.0$ & $>8.0$ \\
$\mathrm{Mn}\left(\mathrm{mg} \mathrm{kg}^{-1}\right)$ & $<2$ & $2-4$ & $>4$ \\
$\mathrm{Zn}\left(\mathrm{mg} \mathrm{kg}^{-1}\right)$ & $<1.2$ & $1.2-1.8$ & $>1.8$ \\
$\mathrm{Cu}\left(\mathrm{mg} \mathrm{kg}^{-1}\right)$ & $<1.2$ & $1.2-1.8$ & $>1.8$ \\
$\mathrm{~B}\left(\mathrm{mg} \mathrm{kg}^{-1}\right)$ & $<0.46$ & $0.46-1.0$ & $>1.0$ \\
\hline
\end{tabular}

$107 \mid 10-12$ | 2
Making use of the number of samples in each category, the per cent sample category and Nutrient Index Values (NIV) were computed using the formulae furnished below.

\section{Per cent sample category}

$$
\begin{array}{ll}
\text { Per cent sample } & \begin{array}{l}
\text { No. of samples in Low or } \\
\text { category }
\end{array}=\frac{\text { Medium or High category }}{\text { Total number of samples }} \times 100
\end{array}
$$

\section{Nutrient index values and fertility rating}

Nutrient index value was calculated from the proportion of soils under low, medium, and high available nutrient categories, as represented by

$$
N I V=\frac{\left[\left(P_{H} \times 3\right)+\left(P_{M x} 2\right)+\left(P_{L} \times 1\right)\right]}{100}
$$

Where,

NIV = Nutrient Index Value

$P_{L}, P_{M}$ and $P_{H}$ are the percentage of soil samples falling in the category of low, medium, and high nutrient status and given weightage of one, two, and three, respectively (Ramamoorthy and Bajaj, 1969).

The nutrient index values were rated into various categories viz., low (<1.67), medium (1.67-2.33), and high (>2.33) for OC and available N, P, and K. For available $S$ and micronutrients, the ratings are very low (<1.33), low (1.33-1.66), marginal (1.67-2.00) adequate (2.01-2.33), high (2.34-2.66) and very high (> 2.66).

\section{Generation of thematic soil fertility maps}

Database on soil available nutrient status was generated in Microsoft Excel and the soil fertility maps were prepared at the Department of Remote sensing and GIS, TNAU, Coimbatore by using Arc-GIS software (version 10.6). The thematic maps on available nutrient status were generated by categorizing the fertility status such as 'Low', 'Medium' and 'High' by showing appropriate legend for soil fertility parameters by krigging geostatistical technique.

\section{RESULTS AND DISCUSSION}

\section{Soil Physicochemical Properties}

The overall data (201 nos) (Table 2 ) revealed that the $\mathrm{pH}$ of the soil ranged from 6.75 to 8.87 with a mean value of 7.54 . The electrical conductivity of the analyzed soil samples varied from 0.01 to 1.05 $\mathrm{dSm}^{-1}$ with a mean value of $0.22 \mathrm{dSm}^{-1}$ and was found to be non-saline. The free $\mathrm{CaCO}_{3}$ content in the soil samples ranged from non-calcareous to slightly calcareous in nature (3.65 to $4.23 \%$ ) with a mean value of $4.23 \%$. The organic carbon content of the soil samples ranged from 1.15 to $9.94 \mathrm{~g} \mathrm{~kg}^{-1}$ with a mean of $5.79 \mathrm{~g} \mathrm{~kg}^{-1}$. 
Table 2.Range and mean values of various soil analytical parameters

( $n=201)$

\begin{tabular}{lccccc}
\hline Parameter & Unit & Range & Mean & SD & CV \\
\hline pH & & $6.75-8.87$ & 7.54 & 0.39 & 5.22 \\
E.C & $\mathrm{d} \mathrm{Sm}^{-1}$ & $0.01-1.05$ & 0.22 & 0.18 & 82.1 \\
O.C & $\mathrm{g} \mathrm{kg}^{-1}$ & $1.15-9.94$ & 5.79 & 2.01 & 34.7 \\
Free CaCO & $\%$ & $3.65-5.30$ & 4.23 & 0.23 & 5.40 \\
Available N & $\mathrm{kg} \mathrm{ha}^{-1}$ & $109-252$ & 177 & 28.4 & 16.1 \\
Available P & $\mathrm{kg} \mathrm{ha}^{-1}$ & $10.5-38.1$ & 27.4 & 6.9 & 25.0 \\
Available K & $\mathrm{kg} \mathrm{ha}^{-1}$ & $160-490$ & 343 & 73.1 & 21.3 \\
Available S & $\mathrm{mg} \mathrm{kg}^{-1}$ & $2.97-23.3$ & 11.8 & 4.4 & 37.2 \\
DTPA-Fe & $\mathrm{mg} \mathrm{kg}^{-1}$ & $1.01-12.5$ & 5.11 & 2.09 & 41.0 \\
DTPA-Zn & $\mathrm{mg} \mathrm{kg}^{-1}$ & $0.20-2.95$ & 0.81 & 0.41 & 50.3 \\
DTPA-Mn & $\mathrm{mg} \mathrm{kg}^{-1}$ & $3.98-20.8$ & 11.3 & 3.97 & 35.0 \\
DTPA-Cu & $\mathrm{mg} \mathrm{kg}^{-1}$ & $0.78-8.60$ & 3.24 & 1.58 & 48.9 \\
HWS-B & $\mathrm{mg} \mathrm{kg}^{-1}$ & $1.41-8.76$ & 5.09 & 1.48 & 29.1 \\
\hline
\end{tabular}

\section{Available nutrient status}

The available nutrient status is furnished in Table 2. The available N, P, and K status of the soils ranged from 109 to 252; 10.5 to 38.1 and 160 to $490 \mathrm{~kg} \mathrm{ha}^{-1}$ with a mean of $177,27.4$, and $343 \mathrm{~kg}$ ha $^{-1}$, respectively. The available $S$ content of the soil ranged from 2.97 to $23.3 \mathrm{mg} \mathrm{kg}^{-1}$ with a mean of $11.8 \mathrm{mg} \mathrm{kg}^{-1}$.

The DTPA extractable Fe, Zn, Mn, and Cu content ranged from 1.01 to $12.5 ; 0.20$ to $2.95 ; 3.98$ to 20.8 ; 0.78 to $8.60 \mathrm{mg} \mathrm{kg}^{-1}$ with a mean of $5.11,0.81$, 11.3 and $3.24 \mathrm{mg} \mathrm{kg}^{-1}$ respectively. The hot water soluble boron content varied from 1.41 to $8.76 \mathrm{mg}$ $\mathrm{kg}^{-1}$ with a mean of $5.09 \mathrm{mg} \mathrm{kg}^{-1}$.

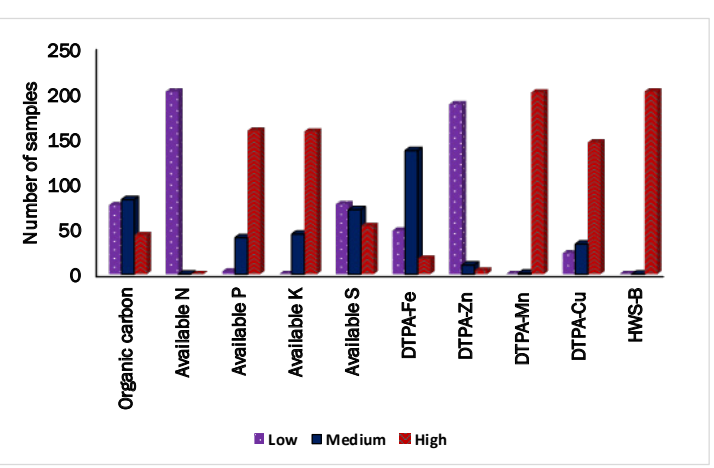

Figure 2. Number of samples under each category of fertility groups

\section{Fertility grouping of soil samples}

The total number of samples belonging to each category of fertility status for every analyzed parameter were worked out and the results are given in Table 3 and Figure 2. Among the 201 soil samples, 104 are neutral and 97 are alkaline in reaction. In the case of EC, all the 201 samples were belonging to the non-saline category. Organic carbon status revealed that out of total samples, 76,82 and 43 soil samples were low, medium, and high category respectively. In the case of available nitrogen, all the 201 samples fell under the category of low status. With respect to available phosphorus, 3,40 , and 158 samples were under the category of low, medium and high status, respectively. In the case of available potassium, 44 and 157 samples were under the category of medium and high status. In the case of available sulphur, 77 samples came under low, 71 samples under medium, and 53 samples under high category. In the case of DTPA micronutrients, 48, 136,17; 187, 10, 4; 0, 1, 200; $23,33,145$ nos of samples were grouped under the low, medium, and high category for DTPA Fe, Zn, Mn, and $\mathrm{Cu}$ respectively. In the case of HWS-B, all the 201 samples fell under the category of high status.

\section{Per cent samples for each fertility group}

Per cent category samples for soil physicchemical properties and available nutrients were worked out and the results are given in Table 3 and Figure 3.

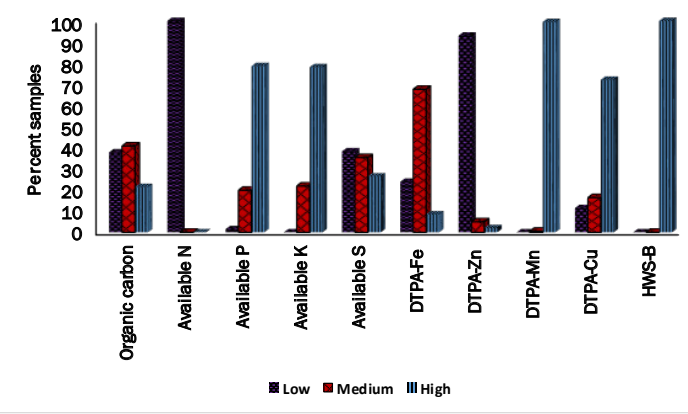

Figure 3. Percent samples under each category of fertility groups

The $\mathrm{pH}$ values of soil samples were neutral (51.7 $\%)$ and alkaline (48.3\%). All the soil samples were categorized under non-saline. Among the 201 soil samples, 37.8, 100, 1.5, 0, and 38.3 per cent of samples were grouped under the low status for O.C, available $\mathrm{N}, \mathrm{P}, \mathrm{K}$, and $\mathrm{S}$, respectively. In the case of micronutrients, 23.9, 93, 0, 11.4, and 0 per cent of samples were grouped under low status for available $\mathrm{Fe}, \mathrm{Zn}, \mathrm{Mn}, \mathrm{Cu}$, and $\mathrm{B}$, respectively.

Table 3. Number and percent samples under each category for $\mathrm{pH}$ and EC

\begin{tabular}{|c|c|c|c|}
\hline \multirow{2}{*}{ Parameters } & \multicolumn{3}{|c|}{ pH } \\
\hline & Acidic & Neutral & Alkaline \\
\hline \multirow{2}{*}{$\mathrm{pH}$} & No. Per cent & No. Per cent & No. Per cent \\
\hline & 0 & 51.7 & 48.3 \\
\hline \multirow{4}{*}{ EC } & \multicolumn{3}{|c|}{ EC } \\
\hline & \multicolumn{2}{|c|}{ Saline } & Non saline \\
\hline & No. & Per cent & No. Per cent \\
\hline & 0 & 0 & $201 \quad 100$ \\
\hline
\end{tabular}


Among the 201 soil samples, 40.8, 0, 19.9, 21.9 and 35.3 percent of samples are with medium status for O.C, available N, P, K, and S, respectively. Among the micronutrients, $67.7,5,0.5,16.4$, and 0 per cent of samples were classified under medium status for available $\mathrm{Fe}, \mathrm{Zn}, \mathrm{Mn}, \mathrm{Cu}$, and $\mathrm{B}$.

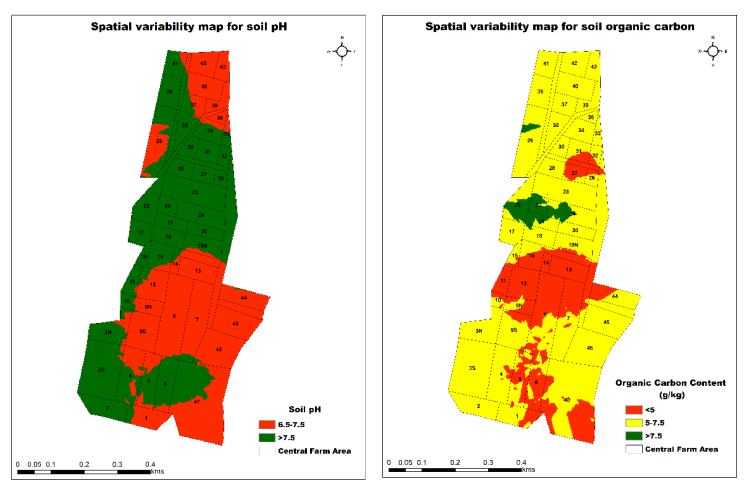

Figure 4. Spatial variability maps for the soil pH and organic carbon

High category found to be with 21.4, 0, 78.6, 78.1 and 26.4 per cent of samples in O.C, available $\mathrm{N}, \mathrm{P}, \mathrm{K}$ and $\mathrm{S}$ respectively. Micronutrients viz., Fe, $\mathrm{Zn}, \mathrm{Mn}, \mathrm{Cu}$, and $\mathrm{B}$ recorded 8.5, 2.0, 99.5, 72.1, and 100 per cent of samples were under the high category.

\section{Nutrient index values}

Nutrient index values for all available nutrient statuses were calculated separately besides organic carbon status (Table 4).

Table 4. Nutrient index value and fertility status

\begin{tabular}{ccc}
\hline Parameters & Nutrient index value & Fertility status \\
\hline O.C & 3.69 & High \\
Available N & 2.01 & Medium \\
Available P & 5.57 & High \\
Available K & 5.59 & High \\
Available S & 2.01 & Adequate \\
DTPA-Fe & 3.71 & Very high \\
DTPA-Zn & 2.19 & Adequate \\
DTPA-Mn & 6.02 & Very high \\
DTPA-Cu & 5.24 & Very high \\
HWS-B & 6.03 & Very high \\
\hline
\end{tabular}

Among the major nutrients, nitrogen registered the lowest nutrient index value of 2.01 followed by phosphorus (5.57) and potassium (5.59). Among the micronutrients, the order of nutrient index value was $\mathrm{Mn}>\mathrm{B}>\mathrm{Cu}>\mathrm{Fe}>\mathrm{Zn}$. Nutrient index for available $\mathrm{N}$ was medium and for, organic carbon, available $\mathrm{P}$, and $\mathrm{K}$, the nutrient index were high. Available sulphur was found to be adequate. Among the micronutrients, DTPA-Fe was classified under the very high category. DTPA-Zn was adequate and while $\mathrm{Mn}, \mathrm{Zn}$, and
Cu were high. Similar studies were carried out by Sellamuthu et al. (2015), Theresa et al. (2019), and Muthumanickam (2020) for assessing the nutrient index values in Tiruchirapalli District, rice ecosystem of Anaimalai Block, and vegetable grown soils of Horticultural College and Research Institute, Periyakulam respectively.
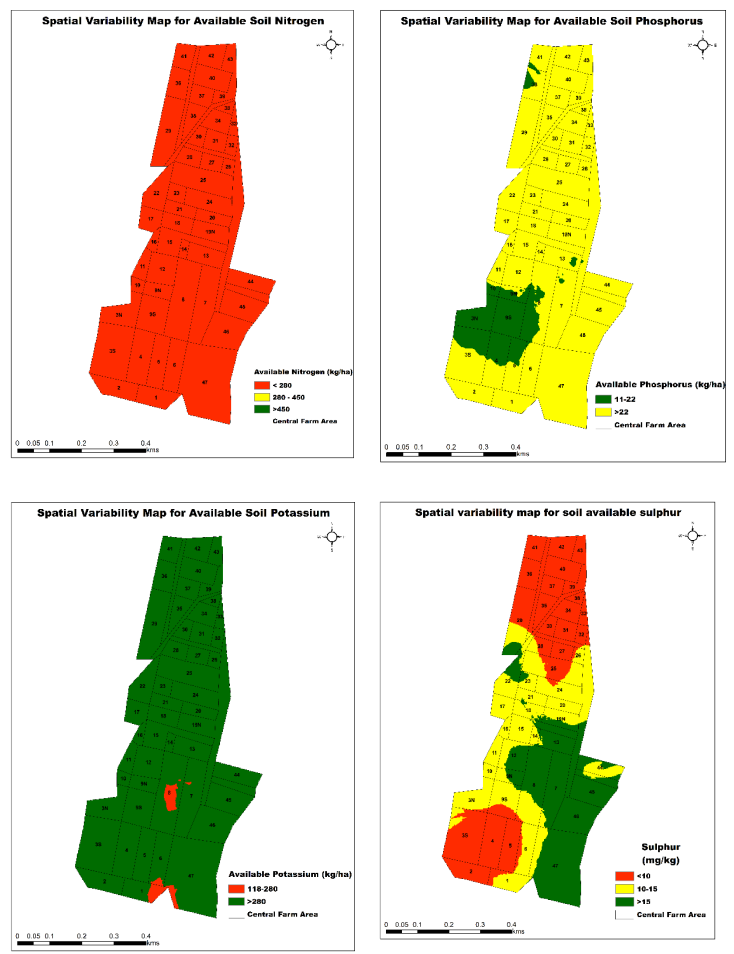

Figure 5. Spatial variability maps for the available soil nitrogen, phosphorus, potassium and sulphur

\section{Thematic soil fertility maps}

The thematic maps on $\mathrm{pH}, \mathrm{EC}$, organic carbon, and available nutrient status were generated by showing appropriate legends for soil fertility parameters (Figures 4-6). Maps were generated and visual differences were clearly depicted the spatial variability of soil fertility parameters in the Central farm of Horticultural College and Research Institute, Periyakulam, Tamil Nadu. Similar studies were carried out by Arunkumar and Paramasivan, (2015) for Veeranam Command Area, Tamil Nadu. Similar thematic maps were created in vegetablegrown soils of Horticultural College and Research Institute, Periyakulam (Muthumanickam,2020). Mapping Soil Fertility and its Spatial Variability in Tiruchirapalli District, Tamil Nadu Using GIS.

\section{CONCLUSION}

Soils of Central farm of Horticultural College and Research Institute, Periyakulam were neutral to alkaline in reaction, non-saline, and slightly calcareous to non-calcareous in nature. Soil fertility groupings with per cent sample in each category 
revealed the dominance of medium in organic carbon, low in available nitrogen, medium to high in available phosphorus, high in available potassium, and low to medium in available sulphur. With respect to soil available micronutrients, the dominance of medium category in DTPA-Fe, low in DTPA-Zn, and high in DTPA- $\mathrm{Cu}, \mathrm{Mn}$, and HWS-B were observed.
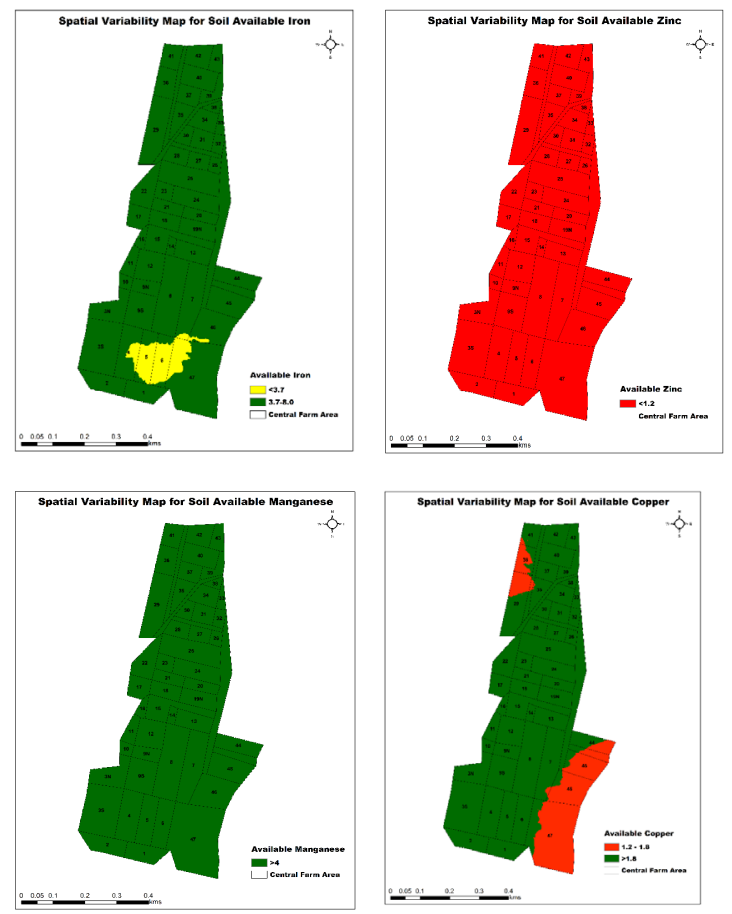

Figure 6. Spatial variability maps for the DTPA- Fe, $\mathbf{Z n}, \mathbf{M n}$ and $\mathbf{C u}$

GIS found to be an essential tool in ceating visual images for a better understanding of soilrelated constraints and to generate location specific management strategies for enhancing soil productivity. Continuous application of organic manures or in-situ application of green or green leaf manures is necessary to improve the soil organic matter content and enhance nutrient use efficiency. The deficient nutrients have to be restored through chemical fertilizers and/or organic manures. Soil test-based fertilizer recommendations along with micronutrients is to be followed for sustained crop production and soil fertility.

\section{AUTHOR CONTRIBUTIONS}

The research work was carried out with funding from Tamil Nadu Agricultural University, Coimbatore. The idea conceptualization, conduct of experiments, and writing of the original draft were done by K.M.Sellamuthu. Mapping with Arc-GIS was carried out by R.Kumaraperumal. Writing, reviewing, and editing the original draft was carried out by P.Malathi.

\section{REFERENCES}

Arunkumar, V. and Paramasivan, M. 2015. Spatial variability and geostatistics application for mapping of soil properties and nutrients in intensively cultivated village of Veeranam Command Area, Tamil Nadu. An Asian J. of Soil Sci., 10 (2):299305.

Berger, K. C. and Troug ,E. 1944. Boron test and determination for soils and plants. Soil Sci., 57: $25-26$.

Jackson, M.L. 1973. Soil chemical analysis. Prentice hall of India Pvt Ltd., New Delhi.p.496

Kasthuri Thilagam, V. and Sivasamy, R. 2013. Role of remote sensing and GIS in land resource inventory-a review. Agri. Reviews, 34 (3) : 223-229.

Lindsay, N.L. and Norvell, W.A. 1978. Development of DTPA soil test for zinc, iron, manganese and copper. Soil Sci. Soc. Am. J., 42: 421-428.

Muthumanickam, D. 2020. Spatial variability mapping of available nutrient status in vegetable grown soils using GIS Techniques. Int. J. Curr. Microbiol. App. Sci. 9(5): 3227-3236.

Olsen, S. R., Cole C. V., Watanabe, P. S. and Dean. L. A. 1954. Estimation of available phosphorus in soils by extraction with sodium bicarbonate. U.S.D.A. Circ., 939.

Ramamoorthy, B. and Bajaj, J.C. 1969. Available N, $\mathrm{P}$ and $\mathrm{K}$ status of Indian soils. Fertilizer News., 14: $24-26$.

Sellamuthu, K.M., Santhi, R., Sivagnanam, S., Radhika, K., Sekar, J., Pradip Dey and Subba Rao, A. 2015. Mapping soil fertility and its spatial variability in Tiruchirapalli district, Tamil Nadu using GIS. Madras Agric. J., 102 (10-12): 317-324.

Sharma P K. 2004. Emerging technologies of remote sensing and GIS for the development of spatial data structure. J. Indian Soc. Soil Sci., 52 (4): 384-406.

Stanford, S. and L. English. 1949. Use of Flame photometer in rapid soil test for $\mathrm{K}$ and $\mathrm{Ca}$. Agron. J., 41: 446-447.

Subbiah, B. V. and G. L. Asija. 1956. A rapid procedure for estimation of available nitrogen in soils. Curr. Sci., 25: 259-260.

Theresa, K., Shanmugasundaram, R. and Kennedy, J.S..2019. Assessment of spatial variability of soil nutrient status in rice ecosystem using Nutrient Index in Anaimalai Block, Coimbatore. Int. J. Curr. Microbiol. App. Sci. 8(8): 2169-2184.

Walkley, A. and Black, I.A. 1934. An examination of soil organic carbon by chromic acid titration method. Soil Sci., 37: 29.

Williams, C.H. and Steinbergs, H. 1959. Soil sulphur fractions as chemical indices of available sulphur in some Australian soils. Australian J. Agric. Res., 10: 340-352. 